\title{
Performance and Host Association of Spotted Lanternfly (Lycorma Delicatula) among Common Woody Ornamentals
}

\section{Osariyekemwen Uyi}

University of Benin

Keller Joseph A.

Pennsylvania State University

Kelli Hoover ( $\nabla$ kxh25@psu.edu )

Pennsylvania State University

\section{Research Article}

Keywords: performance, preference, offspring, fitness, Ailanthus altissima, insect-plant 17 interactions.

Posted Date: April 14th, 2021

DOI: https://doi.org/10.21203/rs.3.rs-397670/v1

License: (1) This work is licensed under a Creative Commons Attribution 4.0 International License.

Read Full License

Version of Record: A version of this preprint was published at Scientific Reports on August 4th, 2021. See the published version at https://doi.org/10.1038/s41598-021-95376-x. 
1 Performance and host association of spotted lanternfly (Lycorma delicatula) among common

2 woody ornamentals

3

4 Osariyekemwen Uyi ${ }^{1,2}$, Joseph A. Keller ${ }^{1} \&$ Kelli Hoover ${ }^{1 *}$

5

$6 \quad{ }^{1}$ Department of Entomology, Pennsylvania State University, University Park, PA 16802, United

7 States of America

$8 \quad{ }^{2}$ Department of Animal and Environmental Biology, University of Benin, P.M.B. 1154, Benin 9 City, Nigeria

10

11

12

13

14

15 16

17

18

19

20

21

22

23

24

25

26

20
2
*Correspondence: Kelli Hoover, Department of Entomology, 501 ASI Building, Pennsylvania State University, University Park, PA 16802, United States of America E-mail: kxh25@psu.edu

Running title: Performance of spotted lanternfly among woody ornamentals

Keywords: performance; preference; offspring; fitness; Ailanthus altissima; insect-plant interactions

9

3




\section{Abstract}

28 Despite the broad host range of Lycorma delicatula, the performance of this invasive pest on

non-Ailanthus host plant species is difficult to document realistically without using field conditions given this pest's requirements for vast amounts of phloem. In spring 2020, we examined the performance of $L$. delicatula with and without access to Ailanthus altissima by tracking development, survival, host tree association and oviposition in large enclosures planted with one each of Juglans nigra, Salix babylonica and Acer saccharinum along with either one $A$. altissima or one Betula nigra. We reared nymphs with and without access to A. altissima, released them into the corresponding large enclosures as third instars, and monitored them from early July 2020 through November 2020. Insect survival was higher and development faster with access to $A$. altissima. Third and fourth instar nymphs were most frequently observed on $A$. altissima when it was present, while adults were equally associated with $A$. saccharinum and $A$. altissima. In the absence of $A$. altissima, nymphs were most frequently found on $S$. babylonica, while adults were most often on $A$. saccharinum. Females with access to A. altissima deposited nearly 7-fold more egg masses than those without access to A. altissima. In another experiment, the offspring of parents that had been reared without access to A. altissima showed similar survival and development time from egg to adult as offspring from parents that never had access to A. altissima. These findings suggest that managers need to be aware that even in the absence of $A$. altissima in the landscape, several hardwood host trees can be utilized by L. delicatula to develop and reproduce.

Keywords: performance, preference, offspring, Lycorma delicatula, Ailanthus altissima, insectplant interaction 


\section{Introduction}

53 Since 2014, the spotted lanternfly (SLF), Lycorma delicatula (White) (Hemiptera: Fulgoridae),

54 an exotic planthopper, has invaded nine states in the Northeast, mid-West, and mid-Atlantic

55 regions of the U.S. Native to China, Taiwan and Vietnam, L. delicatula has also expanded its

56 range to include South Korea and Japan [1-4]. Following its initial detection in Berks County,

57 Pennsylvania (Barringer et al. 2015), L. delicatula has spread to New Jersey, New York,

58 Virginia, Maryland, Delaware, West Virginia, Connecticut, and Ohio [4-5]. The invasion success

59 of this pest may be partly due to its apparent capacity for dispersal [6-7] and its potential to

60 occupy a wide range of climatic conditions and ecosystems, especially disturbed habitats where

61 the preferred host Ailanthus altissima (Mill.) Swingle (Simaroubaceae) (tree-of-heaven) is

62 abundant $[3,8,9]$.

63

64 As a generalist phloem feeder, L. delicatula has proven to be a prominent pest in forest and

65

66

67

68

69

70

71

72

73

agricultural ecosystems and a nuisance pest in suburban landscapes, causing significant

economic losses to vineyards, nurseries, and sawmills in the invaded regions $[4,10]$. For the

ornamentals and forest products industries, the major economic impacts are primarily due to the cost of best management practices to comply with quarantine restrictions, and in some cases, reduced sales [10-11]. Lycorma delicatula is projected to cause $\$ 42.6$ million in damages annually if it spreads across Pennsylvania [11]. Although studies on the impacts of feeding by $L$. delicatula on host plant health are in their infancy, phloem feeding by nymphs and adults is known to cause physiological stress in young stems that may in turn cause infested branches to wilt, lose vigor or die following heavy infestations $[10,12]$. Feeding by L. delicatula results in 
the production of copious amounts of honeydew, which promotes the growth of sooty mold on plants below feeding sites, impeding photosynthesis of affected plants [13-16]. Damage caused by L. delicatula decreases grapevine growth, reducing crop yield by up to $90 \%$ and sometimes killing the vines (Vitis spp. L. [Vitales: Vitaceae]) [10, 12]. Additionally, L. delicatula poses a threat to the growth of several hardwood trees, including silver maple (Acer saccharinum L. [Sapindaceae]), red maple (A. rubrum L. [Sapindaceae]), black walnut (Juglans nigra L. [Juglandaceae]), weeping willow (Salix babylonica L. [Salicaceae]), river birch (Betula nigra L. [Betulaceae]) and tulip tree (Liriodendron tulipifera L. [Magnoliaceae]) [1, 2, 17-19].

Lycorma delicatula prefers A. altissima in both its native and invasive ranges, though it can utilize over 103 plant species across 33 families [4, 17, 18]. In North America, feeding by $L$. delicatula has been observed on 56 plant species, which include native, cultivated, and nonnative species [18]. The rapid spread of this pest is likely facilitated by the prevalence of $A$. altissima, in addition to other suitable host plant species [18]. Despite the broad host range of L. delicatula, basic information is lacking on its host preferences and relative performance when feeding on common woody ornamentals (but see [19-20]). Our previous study in 2019 [19] found that it can complete development and reproduce on young weeping willow (S. babylonica), silver maple ( $A$. saccharinum L) and river birch (B. nigra) without access to A. altissima. Development to adult was delayed by one week and the number of egg masses laid by females were significantly fewer in enclosures with no access to A. altissima. It is, however, unclear whether L. delicatula without access to $A$. altissima can perform as well as those with $A$. altissima if provided larger trees to provide a greater quantity of phloem. Thus, in 2020, we investigated the performance and host association of $L$. delicatula among planted common woody ornamentals that were larger in 2020 
97 than in 2019. A further objective of this study was to determine whether offspring $\left(\mathrm{F}_{1}\right.$ generation) from parents that were reared from egg to adult without access to A. altissima suffer any lingering fitness effects as they develop into adults.

\section{Materials and methods}

102 Origin and maintenance of trees and insect cultures.

103 In Macungie, Berks County, PA, we set up ten $5.76 \mathrm{~m}^{2}$ plots in mid-September 2018; five plots 104 each were randomly allocated to two treatments: 'with Ailanthus' and 'without Ailanthus' [19]. 105 All plots contained one $S$. babylonica, one $A$. saccharinum, and one $J$. nigra spaced $1 \mathrm{~m}$ apart; in 106 addition, the 'with Ailanthus' plots were also planted with one A. altissima, while the 'without 107 Ailanthus' plots contained one river birch (B. nigra) in place of A. altissima. We purchased the 108 Salix babylonica and B. nigra as 15-gallon potted trees at New Hanover Gardens

109 (Perkiomenville, PA), and A. saccharinum as 7-gallon and J. nigra as 2-gallon trees from 110 Octoraro Native Plant Nursery (Kirk, PA). Since A. altissima is a ubiquitous invasive plant, 111 small trees were dug up and transplanted from a local property with the owner's permission. We 112 selected these species because they common in this region of the U.S. and are often used as hosts 113 trees by L. delicatula in Pennsylvania. L. delicatula were confined to each plot using a 114 rectangular screen enclosure made of PAK25 Anti-Insect Mesh (Hummert International, MO) 115 attached to a frame $(3 \times 2.4 \times 2.4 \mathrm{~m})$ made of galvanized steel tubes $(38 \mathrm{~mm}$ diameter $)$ at each 116 corner to prevent collapse during windy thunderstorm. To obtain access to each enclosure we 117 instaleed a $1.8 \mathrm{~m}$ zipper on one side. To prevent $L$. delicatula nymphs or adults from escaping 118 from the enclosures, sandbags $(7.6 \times 99 \mathrm{~cm})$ were sewn into the bottom edge of the enclosure to 
weigh down the sides. We installed drip irrigation connected to the well on the property. In the early spring, trees were pruned to minimize crowding.

In January 2020, egg masses of $L$. delicatula were field collected in Allentown, PA and kept in two pop-up cages $(90 \times 60 \times 60 \mathrm{~cm})$ under ambient environmental conditions in an unheated greenhouse in Macungie, PA. In early May, egg masses were transferred to 20 pop-up cages ( 90 $\times 60 \times 60 \mathrm{~cm})$ containing potted host plants and housed under a canopy at the experimental site. In this way, all plants received direct sunlight for part, but not all, of the day. These pop-up cages were divided between two treatments: 'with Ailanthus' (10 cages) and 'without Ailanthus' (10 cages). Pop-up cages 'with Ailanthus' contained one potted $\sim 60 \mathrm{~cm}$ tall A. altissima (planted from field-collected seeds), one potted $\sim 45 \mathrm{~cm}$ tall $V$. vinifera (cv. Cabernet-Franc; Hermann J. Wiemer Vineyard, Dundee, NY), one potted $\sim 45 \mathrm{~cm}$ tall strawberry and one potted $\sim 45 \mathrm{~cm}$ tall sunflower, while pop-up cages 'without Ailanthus' contained one potted $\sim 45 \mathrm{~cm}$ tall $V$. vinifera, strawberry and sunflower. Neonates in both treatments were reared to third instar until release into each multi-tree enclosure.

\section{Experiment I: Lycorma delicatula survival, development and host plant associations.}

Between July 7 and July 10, 2020, 120 third instars were released into each multi-tree enclosure.

Enclosures 'with Ailanthus' received nymphs with prior access to A. altissima from the pop-up cages with potted A. altissima (see details above) and vice versa [19]. Each week we monitored plots for survival, life stage, and which host tree the insects were found on by counting the numbers of nymphs (from July 15, 2020 to September 2, 2020) and adults (August 12, 2020 to November 4, 2020) present on each host tree species and on other surfaces in each enclosure. 
142 After reaching adulthood, we began monitoring and recording for oviposition weekly from

143 through November 4, 2020 when a hard freeze killed all remaining adults.

145 To determine how L. delicatula feeding affected tree growth, we measured trunk diameters at 10

$146 \mathrm{~cm}$ above the soil line using a caliper on July 8, 2020 before releasing L. delicatula into the

147 enclosures and on November 3,2020 at the end of the experiment. To document growth between 1482019 and 2020, we compared trunk diameter of trees by species between 2019 and 2020 on June

1494 and October 31. Trunk diameter measurements for J. nigra were not available because most of 150 these trees had died during the 2019 studies and were replaced in spring of 2020.

152 Experiment II: Performance of $L$. delicatula offspring.

153 To compare fitness of offspring from parents that did or did not have access to $A$. altissima trees

154 during development from egg to adult, we collected egg masses from the prior experiment (as 155 above) conducted in 2019 [19]. In early-June of 2020 these egg masses were carefully collected

156 from the trees in each multi-tree plot, placed in Petri dishes and held in pop-up cages $(90 \times 60 \times$ $15760 \mathrm{~cm}$ ) containing two potted $A$. altissima trees, with 4 replicates per treatment. The pop-up 158 cages were placed in open field conditions in the same location but were sheltered from direct 159 rainfall. Trees were watered thrice per week and replaced once per month with fresh potted $A$. 160 altissima trees. Weekly, we recorded survival and development of $L$. delicatula by counting the 161 numbers of nymphs and adults present in each cage.

162 Statistical analysis.

163 To evaluate the effect of the presence or absence of A. altissima on the survival of L. delicatula 164 in Experiments I and II, we fit a generalized linear mixed model with a binomial error 
165 distribution and logit link function using the glmmTMB function [19] in R [21-22]. Our model

166 included treatment, date of observation, and the interaction between these two factors as

167 predictors, and cage as a random effect to account for repeated observations. Similarly, to assess

168 the effect of $A$. altissima presence on the timing at which individuals reached the fourth instar

169 and adulthood in Experiments I and II, we fit a GLM mixed effects model with a binomial error

170 distribution and a logit link function. We predicted the proportion of individuals in each cage that

171 had reached the fourth instar and adult stages based on the date, treatment (with or without $A$.

172 altissima) and interaction of these two factors. We again included cage as a random effect in the

173 model to account for repeated observations. We assessed the significance of the treatment by

174 conducting a likelihood ratio test to compare the full model against a reduced model, excluding

175 treatment as a predictor. Repeated measures GLM ANOVA was used to compare the host plant

176 association (i.e., the proportion of nymphs and adults of L. delicatula on a given tree species) of

177 L. delicatula in the presence or absence of $A$. altissima using SPSS version 20.0 (IBM, SPSS Inc.

178 Chicago, IL). If the overall model was significant, differences between trees was determined

179 using the Bonferroni post hoc test. The Mann Whitney U test was used to compare the number of 180 eggs masses between treatments using SPSS version 20.0. The impact of L. delicatula feeding on

181 trunk diameter and trunk diameter growth of tree species between 2019 and 2020 was evaluated

182 with a GLM ANOVA using SPSS version 20.0. If the overall model was significant, differences

183 between trees was determined using the Bonferroni post hoc test. Juglans nigra trees were not

184 included in the analysis because most died during the 2019 studies and had to be replaced in 185 spring of 2020.

186

187 Results 

saccharinum (Fig. 5c).

\section{Survival, development time, host association and egg mass count.}

Following release into multi-tree enclosures, the proportion of individuals of L. delicatula (from third instar nymph to adult) that survived was approximately $10 \%$ higher in enclosures with $A$. altissima compared to the non-Ailanthus enclosures throughout the season $\left(\chi^{2}=16.29, \mathrm{df}=1, P=\right.$ 0.001; Fig. 1). Third instar nymphs in A. altissima enclosures developed slightly faster to fourth instar $\left(\chi^{2}=56.26, \mathrm{df}=1, P=0.001\right.$; Fig. 2); fitted logistic regression curves showed that $50 \%$ of third instars with Ailanthus reached the fourth instar 2.1 days earlier than those without Ailanthus. In cages containing A. altissima $50 \%$ of fourth instars reached adulthood 8.4 days earlier than those in enclosures without $A$. altissima $\left(\chi^{2}=9.67 ; P=0.001\right.$; Fig. 3$)$.

Host plant association of third and fourth instar nymphs as well as adults in A. altissima enclosures were influenced by the available tree species but did not differ over time (Table 1; Fig. 4a-c). In enclosures with $A$. altissima, third instars were most frequently observed on $A$. altissima (Fig. 4a), while fourth instars were found with equal frequency on A. altissima, $S$. babylonica and A. saccharinum (Fig. 4b). Adults were mostly observed on A. saccharinum despite the presence of $A$. altissima (Fig. 4c). In enclosures without $A$. altissima, host plant association of nymphs and adults differed as a function of tree species but did not differ over time (Table 2; Fig. 5a-c). In enclosures without A. altissima, third instars were most frequently observed on S. babylonica (Fig. 5a), while fourth instars were found with equal frequency on $S$. 
Table 1. Repeated measures binomial GLM ANOVA for data on the effect of tree species and time on the proportion of Lycorma delicatula nymphs and adults present on individual trees in cages where they had access to Ailanthus altissima.

\begin{tabular}{llllll}
\hline Variable & Source of variation & df & MS & F-value & P-value \\
& & & & & \\
\hline Third instars & Tree species & 3 & 3495 & 11.20 & $\mathbf{0 . 0 0 1}$ \\
& Time & 16 & 0.023 & 0.001 & 0.999 \\
& Tree species $\times$ Time & 9 & 388.3 & 1.24 & 0.301 \\
& Error & 59 & & & \\
Fourth instars & Tree species & 4 & 5218 & 20.68 & $\mathbf{0 . 0 0 1}$ \\
& Time & 5 & 0.067 & 0.011 & 0.967 \\
& Tree species $\times$ Time & 20 & 414.2 & 1.84 & 0.061 \\
Adults & Error & 3 & 14347 & 13.45 & $\mathbf{0 . 0 0 1}$ \\
& Tree species & 11 & 1.03 & 0.009 & 0.991 \\
& Time & 33 & 358.9 & 2.98 & 0.063 \\
& Tree species $\times$ Time & 33 & & \\
\hline
\end{tabular}

df: degrees of freedom; MS: mean squares.

214 Statistically significant values are indicated in bold.

215

216

217

218

219

220

221

222

223

224

225

226

227

228

229

230

231

232

233

234

Table 2. Repeated measures binomial GLM ANOVA for analysis of data on the effect of tree species and time on the proportion of Lycorma delicatula nymphs and adults present on individual trees in cages without Ailanthus altissima.

\begin{tabular}{llllll}
\hline Variable & Source of variation & df & MS & F-value & P-value \\
& & & & \\
\hline Third instars & Tree species & 3 & 1241 & 10.42 & $\mathbf{0 . 0 0 1}$ \\
& Time & 3 & 0.09 & 0.05 & 0.970 \\
& Tree species $\times$ Time & 9 & 292.3 & 2.45 & 0.057 \\
\hline
\end{tabular}




\begin{tabular}{llllll}
\hline \multirow{3}{*}{ Fourth instars } & Error & 59 & & & \\
& Tree species & 4 & 4071 & 8.22 & $\mathbf{0 . 0 0 1}$ \\
& Time & 5 & 0.021 & 0.001 & 0.999 \\
Tree species $\times$ Time & 20 & 342.5 & 1.42 & 0.129 \\
Adults & 100 & & & \\
& Error & 3 & 14352 & 13.05 & $\mathbf{0 . 0 0 1}$ \\
& Tree species & 11 & 0.32 & 0.003 & 0.993 \\
& Time & 33 & 3231 & 2.11 & 0.071 \\
\hline & Tree species $\times$ Time & 176 & & & \\
\hline
\end{tabular}

235

236

237

238

239

240

241

242

243

244

245

246

247

248

249

250

\section{Impact of Lycorma delicatula feeding on tree species.}

252 For both treatments, trunk diameter differed significantly by year ('with Ailanthus': $F_{1,29}=79.27$;

$253 P=0.0001$; 'without Ailanthus': $\left.F_{1,29}=40.84 ; P=0.0001\right)$ and tree species ('with Ailanthus':

$254 \quad F_{2,29}=45.47 ; P=0.0001 ;$ 'without Ailanthus': $\left.F_{2,29}=101.87 ; P=0.0001\right)$. There were no 
255 significant tree species $\times$ year interactions ('with Ailanthus': $F_{2,29}=1.15 ; P=0.334$; 'without

256 Ailanthus': $F_{2,29}=2.25 ; P=0.070$ ). Trees used in 2020 were on average $26.0 \pm 2.3 \%$ larger than

257 the same trees were in 2019 (Fig. 6a and b). Trunk diameter increase differed significantly by

258 year ('with Ailanthus': $F_{1,29}=14.47 ; P=0.0001$; 'without Ailanthus': $F_{1,29}=13.25 ; P=0.0001$ )

259 but not by tree species ('with Ailanthus': $F_{2,29}=1.51 ; P=0.252$; 'without Ailanthus': $F_{2,29}=0.10$;

$260 P=0.903)$. There were no significant tree species $\times$ year interactions ('with Ailanthus':

$261 \quad F_{2,29}=0.11 ; P=0.899 ;$ 'without Ailanthus': $\left.F_{2,29}=3.10 ; P=0.057\right)$. Trees in both treatments and

262 of every species except river birch grew $\geq 2$-times more in diameter in 2019 on average than the

263 same trees grew in 2020; river birch grew 1.2-times more in 2019 than in 2020 (Figs. 7a and b).

264

265 Offspring performance.

266 After being released in popup cages with access to healthy A. altissima, the proportion of

267 hatched offspring from eggs laid the previous fall did not differ as a function of parental diet $\left(\chi^{2}\right.$

$268=0.70, \mathrm{df}=1, P=0.401)$. Development time (hatch to adults) also did not differ between

269 offspring from parents with or without access to A. altissima $\left(\chi^{2}=0.13\right.$, $\left.\mathrm{df}=1, P=0.722\right)$.

270

\section{Discussion}

272 Lycorma delicatula can complete development and reproduce without access to A. altissima,

273 confirming our findings from the previous year [19], and providing additional insight into host

274 association and the impact of $L$. delicatula on diameter growth of common woody ornamental

275 trees in response to feeding pressure from L. delicaulta. Fitness of the insect was greater in the

276 presence of $A$. altissima. Survival was higher, development time was faster, and the number of

277 egg masses was 6.8-fold higher than for insects that lacked access to A. altissima. This study 
278 also showed that offspring from parents that had been reared without access to $A$. altissima did

279 not suffer fitness effects into the next generation. We hypothesize that reduced egg mass

280 production in cages without Ailanthus was caused by slower development resulting in a shorter

281 time span between adult emergence and freezing-induced mortality during which adults can mate

282 and lay eggs. However, in southern climates where freezing temperatures appear several months

283 later in the year or not at all, lack of access to A. altissima may have less impact on fitness since

284 there could be time for slower developing adults to continue oviposition into the early winter.

285

286 In this study, survival to adult was high for both treatments (with and without Ailanthus),

287 although survival was slightly higher (10\% difference) in the presence of $A$. altissima. By early

288 September 2020, approximately $63 \%$ of the individuals released in A. altissima enclosures and

289 non-Ailanthus enclosures were still alive. This is in contrast to our 2019 study where survival on

290 younger, smaller trees was less than $20 \%$ for both treatments (with and without Ailanthus) by

291 September 2 when most lanternflies were adults [19]; however, the previous study started with

292 the release of newly hatched first instars. Lower survival in 2019 could have been due to early

293 mortality of first and second instar nymphs and/or having access to smaller trees in 2019 than in

2942020 in that larger and vigorous trees may provide a greater volume of phloem and nutrients over

295 time.

296

297 The faster development time of L. delicatula in enclosures with $A$. altissima suggests that adults

298 could reach sexual maturity faster in areas where $A$. altissima is abundant. Development time

299 remains one of the most crucial fitness indicators of host plant nutritional quality and can

300 influence insect survival, behavior and physiology [23]. For example, several studies have found 
301 that slow development in phytophagous insects can cause high mortality of immature stages in

302 the field by exposing them to unfavorable environmental conditions for a longer time period [24-

303 25]. A key fitness cost caused by prolonged development in L. delicatula was narrowing of the

304 reproductive window for adults, which was reflected in markedly fewer eggs being laid before

305 freezing temperatures killed the remaining adults [19].

306

307 Third and fourth instar nymphs were mostly associated with A. altissima when it was present,

308 however, more adults were found on A. saccharinum than on A. altissima when both tree species

309 were present. This may occur when the pest has exhausted the ability of $A$. altissima to provide

310 sufficient sap flow, which also coincides with the onset of senescence of this tree species in mid-

311 September. In the absence of A. altissima, B. nigra, A. saccharinum, J. nigra and S. babylonica

312 together appeared to provide sufficient nutrition for growth and reproduction, but sap flow may

313 be lower in these species, which could explain the delayed development time in the absence of $A$.

314 altissima. However, we cannot rule out that if given access to mature and vigorous suitable hosts

315 such as $A$. saccharinum or A. rubrum, sexual maturity could have occurred at the same rate as

316 those with access to A. altissima. These two maple species are heavily utilized by L. delicatula

317 adults in the field in the fall (D.D. Calvin et al. unpublished data). Although the trees in our study

318 were significantly larger than they were the previous year, they were still smaller than trees that

319 are selected by wild populations of $L$. delicatula adults in the field where profuse feeding is

320 associated with reproductive maturation (pers. observations).

321

322 Several factors ranging from sap flux to host-tree bark characteristics and the presence or

323 absence of defensive chemicals may influence feeding preference in L. delicatula [26-27]. For 
example, L. delicatula has been reported to survive longer on, and prefer, host trees with a high concentration of sugars similar to those produced by A. altissima and $V$. vinifera [28]. In prior work by Lee and colleagues [19], the authors reasoned that the improved performance on and preference for $A$. altissima and $V$. vinifera is related to high concentrations of sucrose and glucose in A. altissima phloem, and high proportions of sucrose and fructose in V. vinifera phloem. Several authors have also noted that $L$. delicatula seems to prefer hosts with trunks and branches that do not have thick bark but have high sap turgor pressure, allowing for ingestion of phloem at a greater rate $[17,18,20]$. The trees used in our study were chosen because they are frequently infested in the field and do not have the thick bark that occurs on oak trees, for example, which are infrequent hosts [29].

Although egg masses were laid on all host trees as well as planks and logs, S. babylonica, $A$. saccharinum, and A. altissima were generally preferred for oviposition. Oviposition substrate selection can be vital to the reproductive success of insect herbivores. The preferenceperformance hypothesis (a.k.a. mother knows best hypothesis) predicts correlation between oviposition preference by the female parent and host suitability for offspring development [3031]. However, it does not translate well to species like L. delicatula with immature stages that are highly mobile or instances where the adults and immature life stages feed on different hosts [32]. Although tree species and branch structure may play a role in the selection of sites for oviposition [17], why L. delicatula oviposits on non-living materials remains to be explained. The basis for oviposition preferences is not always easy to empirically verify [31]. Some $L$. delicatula researchers think that females lay most of their eggs in the vicinity of where they fed to fatten up and become reproductively mature because it's harder for them to fly once they've 
347 gained so much weight [33]. Alternatively, as is evident in some insects and mite species [31,

348 34], L. delicatula may be following a strategy where females do not necessarily oviposit on

349 suitable hosts in order to make it harder for predators to find their eggs and early instars.

351 The ability of $L$. delicatula to survive, develop and produce egg masses with or without $A$.

352 altissima may be due to the presence of multiple, suitable host plant species in the enclosures. It

353 is not uncommon for generalist feeders to require diet mixing to acquire the necessary nutrients

354 for development and reproduction [35-36], and L. delicatula appears to demonstrate better fitness

355 when provided multiple suitable host plants. While they can be reared from nymphs to adults on

356 a single species such as $V$. vinifera or $A$. altissima, without diet mixing, adults may not produce

357 eggs. For example, L. delicatula that were reared exclusively on A. altissima or $V$. vinifera failed

358 to produce egg masses, whereas their counterparts that received a combination of both did (Tracy

359 Leskey, USDA/ARS, personal communication).

361 The fact that trunk diameter growth of trees was significantly greater (by $3 \mathrm{~mm}$ ) in 2019

362 compared to 2020 suggests that exposure of host trees to L. delicatula feeding pressure for two

363 seasons in a row may have limited the growth of these trees, although abiotic factors such as

364 climate could play a role. Our results also suggest that economically important ornamentals trees

365 and other indigenous host tree species may be significantly impacted when exposed to feeding

366 pressure for more than one season. Feeding by nymphs and adults of L. delicatula can reduce

367 photosynthesis and carbon storage (Lavely et el. unpublished data; Centinari et al. unpublished

368 data), potentially causing stunted growth and/or mortality of host plants [37-38]. Although

369 feeding by L. delicatula can result in oozing trunk wounds, wilting, branch death, and sooty 
mold [15], the extent of damage and effects of herbivory on woody ornamental trees in North

371 America are only beginning to be investigated. Our results on the impact of L. delicatula feeding

372 should be considered preliminary and need to be interpreted with caution as our study lacked the

373 adequate control (trunk diameter growth) data to make a definitive statement on the impact of $L$.

374 delicatula feeding on host tree species.

375

376 Although L. delicatula developed more slowly without access to A. altissima, the offspring from

377 eggs produced by these adults did not suffer ongoing fitness effects, which could have

378 implications for the spread of this pest in the United States. While range expansion of $L$.

379 delicatula is likely facilitated by the prevalence of A. altissima, it is clear that other hardwood

380 tree species can serve as suitable hosts to support development and reproduction. It's possible

381 that in a warmer southern climate, adults that develop more slowly in a region without $A$.

382 altissima may have time to catch up and lay as many egg masses as they would have if there was

383 access to $A$. altissima. Overall, our findings suggest that managers need to be aware that even in

384 the absence of $A$. altissima in the landscape, several hardwood host trees can be utilized by $L$.

385 delicatula to develop and reproduce.

387 Acknowledgements

388 The authors would like to thank David Long, Anne Johnson, Elizabeth Wagner, Emelie

389 Swackhamer and Scott Alan Swackhamer for assistance during the field study. Funding was

390 provided by Cooperative Agreements with USDA Forest Service Forest Health Protection (Grant

391 18-CA-11420004-198) and USDA APHIS (Award No: AP19PPQS\&T00C080) and grants from

392 the USDA NIFA and McIntire-Stennis Appropriations under Project \#PEN04684 and Accession 
393 \#1018126, the Pennsylvania Department of Agriculture (Grant No. 44187340), and the

394 Horticultural Research Institute. This work was also supported in part by the USDA National

395 Institute of Food and Agriculture and Hatch Appropriations under Project \#PEN04728 and

396 Accession \#1021211.

397

398 Competing interests

399 The author declares no competing interests.

400

401

\section{Data Availability Statement}

402 All relevant data are within the paper

403

404 Author contributions

$405 \mathrm{KH}$ and OU conceptualized and designed the study; OU performed the field experiments; OU

406 and JK performed the statistical analysis; OU wrote the manuscript; KH and JK critically

407 reviewed and amended the manuscript.

408

409 IUCN Policy Statement

410 Collection of plant material was done in compliance with relevant institutional, national, 411 and international guidelines and legislation.

412

413

References

414 1. Barringer, L.E., Donovall, L.R. Spichiger, S.E., Lynch, D \& Henry, D. The first New

415 World record of Lycorma delicatula (Insecta: Hemiptera: Fulgoridae). Entomological

$416 \quad$ News 125, 20-23 (2015).

417 2. Dara, S.K., Barringer, L. \& Arthurs, S.P. Lycorma delicatula (Hemiptera: Fulgoridae): a 
new invasive pest in the United States. Journal of Integrated Pest Management 6, 20 (2015).

3. Jung, J.M., Jung, S., Byeon, D. \& Lee, W. Model-based prediction of potential distribution of the invasive insect pest, spotted lanternfly Lycorma delicatula (Hemiptera: Fulgoridae), by using CLIMEX. Journal of Asia- Pacific Biodiversity 10, 532-538 (2017).

4. Lee, D.-H., Park, Y.-L. \& Leskey, T.C. A review of biology and management of Lycorma delicatula (Hemiptera: Fulgoridae), an emerging global invasive species. Journal AsiaPacific Entomology 22, 589-596 (2019).

5. (NYSIPM) New York State Integrated Pest Management. 2020. Spotted lanternfly. https://nysipm.cornell.edu/environment/invasive-species-exotic- pests/spotted-lanternfly/ (accessed 18 January 21).

6. Park, M., Kim, S.M. \& Lee, J.H. Genetic structure of Lycorma delicatula (Hemiptera: Fulgoridae) populations in Korea: implication for invasion processes in heterogeneous landscapes. Bulletin of Entomological Research 103, 414-424 (2013).

7. Keller, J.A., Johnson, A.E, Uyi, O., Wurzbacher, S., Long, D., \& Hoover, K. Dispersal of Lycorma delicatula (Hemiptera: Fulgoridae) nymphs through contiguous, deciduous forest. Environmental Entomology 49, 1012-1018 (2020).

8. Smyers, E.C., Urban, J.M., Dechaine, J.D., Pfeiffer, D.G., Crawford, S.R., Calvin, D.D. (2020). Spatio-temporal model for predicting spring hatch of the spotted lanternfly (Hemiptera: Fulgoridae). Environmental Entomology 50, 126-137.

9. Wakie, T.T., Neven, L.G., Yee, W.L. \& Lu, Z. The establishment risk of Lycorma delicatula (Hemiptera: Fulgoridae) in the United States and globally. Journal of 
Economic Entomology 113, 306-314 (2019).

10. Urban, J.M. 2020. Perspective: shedding light on spotted lanternfly impacts in the USA. Pest Management Science 76, 10-17.

11. Harper, J.K., Stone, W., Kelsey, T.W. \& Kime, L.F. Potential Economic Impact of the spotted lanternfly on agriculture and forestry in Pennsylvania. The Center for Rural Pennsylvania, Harrisburg, PA. 84p (2019).

12. Song, M.K. Damage by Lycorma delicatula and chemical control in vineyards [M.S. thesis]. Korea: Chunbuk National University. 39p (2010).

13. Tedders, W.L., \& Smith J.S. Shading effect on pecan by sooty mold growth. Journal Economic Entomology 69, 551-553 (1976).

14. Lemos-Filho, J.P.D. \& Paiva, É.A.S. The effects of sooty mold on photosynthesis and mesophyll structure of mahogany (Swietenia macrophylla King., Meliaceae). Bragantia 65,11-17 (2006).

15. Han, J.M., Kim, H.J., Lim, E.J. Lee, S.H., Kwon, Y.J. \& Cho, S.W. Lycorma delicatula (Hemiptera: Auchenorrhyncha: Fulgoridae: Aphaeninae) finally, but suddenly arrived in Korean Entomological Research 38, 281-286 (2008).

16. Park, J.D., Kim, M.Y., Lee, S.G., Shin, S.C., Kim, J.H. and Park, I.K. Biological characteristics of Lycorma delicatula and the control effects of some insecticides. Korean Journal Applied Entomology 48, 53-57 (2009).

17. Liu, H. 2019. Oviposition substrate selection, egg mass characteristics, host preference, and life history of the spotted lanternfly (Hemiptera: Fulgoridae) in North America. Environmental Entomology 48, 1452-1468.

18. Barringer, L.E. \& Ciafré, C.M. Worldwide feeding host plants of spotted lanternfly, with 
significant additions from North America. Environmental Entomology 49, 999-1011

465

466

467

468

469

470

471

472

473

474

475

476

477

478

479

480

481

482

483

484

485

486 (2020).

19. Uyi, O., Keller, J.A., Johnson, A., Long, D., Walsh, B. \& Hoover, K. Spotted lanternfly (Hemiptera: Fulgoridae) can complete development and reproduce without access to the preferred host, Ailanthus altissima. Environmental Entomology 49, 1185-1190 (2020).

20. Murman, K. Distribution, survival, and development of spotted lanternfly on host plants found in north America. Environmental Entomology 49, 1270-1281 (2020)

21. Magnusson, A. glmmTMB: Generalized linear mixed models using template model builder. R package v. 0.1.3. https://github.com/glmmTMB. (2017).

22. R Development Core Team. R: a language and environment for statistical computing co mputer program, version 3.6.3. R Development Core Team, Vienna, Austria (2020).

23. Kariyat, R.R. \& Portman, S.L. Plant-herbivore interactions: Thinking beyond larval growth and mortality. American Journal of Botany 103,1-3 (2016).

24. Fordyce, J.A., \& Shapiro, A.M. Another perspective on the slow-growth/high-mortality hypothesis: chilling effects on swallowtail larvae. Ecology 84, 263-268 (2003).

25. Uesugi, A. 2015. The slow-growth high-mortality hypothesis: direct experimental support in a leaf mining fly. Ecological Entomology 40, 221-228.

26. Song, S., Kim, S., Kwon, S.W., Lee, S-I. \& Jablonski, P.G. 2018. Defense sequestration associated with narrowing of diet and ontogenetic change to aposematic colours in the spotted lanternfly. Scientific Reports 8, 16831 (2018).

27. Domingue, M.J., \& Baker, T.C. Orientation of flight for physically disturbed spotted lanternflies, Lycorma delicatula, (Hemiptera, Fulgoridae). Journal of Asia Pacific Entomology 22, 117-120 (2019). 
28. Lee, J.E., Moon, S.R., Ahn, H.G., Cho, S.R. Yang, J.O., Yoon, C. \& Kim, J.H. Feeding behavior of Lycorma delicatula (Hemiptera: Fulgoridae) and response on feeding stimulants of some plants. Korean Journal of Applied Entomology 48, 467-477 (2009).

29. Liu, H. Seasonal development, cumulative growing degree-days, and population density of spotted lanternfly (Hemiptera: Fulgoridae) on selected hosts and substrates. Environmental Entomology 49, 1171-1184 (2020).

30. Jaenike, J. On optimal oviposition behavior in phytophagous insects. Theoretical Population Biology 14, 350-356 (1978).

31. Gripenberg, S., Mayhew, P.J., Parnell, M. \& Roslin, T. A meta-analysis of preferenceperformance relationships in phytophagous insects. Ecology Letters 13, 383-393 (2010).

32. Fujiyama, N., Torii, C., Akabane, M. \& Katakura, H. Oviposition site selection by herbivorous beetles: a comparison of two thistle feeders: Cassida rubiginosa and Henosepilachnniponica. Entomologia Experimentalis et Applicata 128, 41-48 (2008).

33. Wolfin, M.S., Myrick, A.J. \& Baker, T.C. Flight duration capabilities of dispersing adult spotted lanternflies, Lycorma delicatula. Journal of Insect Behavior 33, 125-137 (2020).

34. Faraji, F., Janssen, A., Sabelis, M.W. Oviposition patterns in a predatory mite reduce the risk of egg predation caused by prey. Ecological Entomology 27, 660-664 (2002).

35. Behmer, S.T. \& Joern, A. Coexisting generalist herbivores occupy unique nutritional feeding niches. Proceedings of the National Academy of Sciences, USA. 105,1977-1982 (2008).

36. Behmer, S.T. Insect herbivore nutrient regulation. Annual Review of Entomology 54, 165-187 (2009).

37. Ding, J, Wu, Y., Zheng, H., Fu, W., Reardon, R. \& Liu, M. Assessing potential biological 
control of the invasive plant, tree-of-heaven, Ailanthus altissima. Biocontrol Sciencecand Technology 16, 547-566 (2006).

38. Anderson, H. et al. Pest risk analysis for Lycorma delicatula (Hemiptera: Fulgoridae). European and Mediterranean Plant Protection Organization 16-21777 (2015).

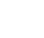

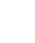

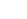

(1)

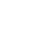
8 9

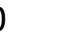

(1)

2

\section{Figure legends}

Figure 1. Proportion of Lycorma delicatula (nymphs and adults combined) that survived in enclosures with planted Ailanthus altissima, Acer saccharinum, Juglans nigra and Salix babylonica ('Ailanthus,' $n=5$ enclosures) or enclosures with the same tree species except for the 50 presence of Betula nigra in place of A. altissima ('without Ailanthus,' $n=5$ enclosures) from 51 July 15 to November 4, 2020. Fitted binomial regression lines are shown, with shaded areas 52 indicating 95\% confidence intervals for predicted regression means. In total, 120 third-instar 53 nymphs were released in each enclosure and their numbers and host tree associations were 54 recorded weekly. 
556

557

558

559

560

561

562

563

564

565

566

567

568

569

570

571

572

573

574

575

576

577

578

579

580

581

582

583

584

585

586

Figure 2. Proportion of $L$. delicatula that developed from the third to the fourth instar over time, with fitted logistic regression lines, in enclosures with and without Ailanthus altissima.

Figure 3. Proportion of $L$. delicatula that emerged as adults over time, with fitted logistic regression lines, for enclosures with and without Ailanthus altissima.

Figure 4. Mean ( \pm SE) proportion of Lycorma delicatula third instars (A) fourth instars (B) and adults (C) present on each tree species in enclosures with Ailanthus (Ailanthus altissima), silver maple (Acer saccharinum), black walnut (Juglans nigra) and willow (Salix babylonica) $(n=5$ enclosures) from July 15 to November 4, 2020. Nymphs and adults found on annual plants (2\%) within the enclosure or on enclosure walls (98\%) are included as 'Others.' Means within a column followed by different letters are significantly different (Bonferroni post hoc test: $P<$ 0.05). No adults were found on black walnut and no third instar nymphs were found on other surfaces.

Figure 5. Mean ( $\pm \mathrm{SE}$ ) proportion of Lycorma delicatula third instars (A), fourth instars (B) and adults (C) present on each tree species in enclosures with silver maple (Acer saccharinum), black walnut (Juglans nigra), willow (Salix babylonica) and river birch (Betula nigra) (without Ailanthus altissima, $n=5$ enclosures) from July 15 to November 4, 2020. Nymphs and adults found on other plants (2\%) within the enclosure or on enclosure walls $(98 \%)$ are included as 'Others.' Means within a column followed by different letters are significantly different (Bonferroni post hoc test: $P<0.05$ ). No adults were found on black walnut and no third instar nymphs were found on other surfaces.

Figure 6. Mean ( $\pm \mathrm{SE})$ trunk diameter $(\mathrm{mm})$ of tree species in enclosures with Ailanthus $(\mathrm{A})$ and without Ailanthus (B) ( $n=5$ enclosures) in 2019 and 2020. Measurements were made on October 31, 2019 and November 3, 2020. Means within a column followed by different letters are significantly different (Bonferroni post hoc test: $P<0.05$ ). Black walnut trees were not included in the analysis because most died during the 2019 studies and had to be replaced in spring of 2020. 
587 Figure 7. Mean $( \pm \mathrm{SE})$ increase in trunk diameter $(\mathrm{mm})$ of tree species in enclosures with

588 Ailanthus (A) and without Ailanthus (B) ( $n=5$ enclosures) in 2019 and 2020. Measurements

589 were made on June 4 and October 31, 2019, and July 8 and November 3, 2020. Increase in trunk

590 diameter was obtained by subtracting trunk diameter data collected at the start of the experiment

591 from those collected at the end of the experiment. Diameter increase did not differ $(P>0.05)$

592 between species in 2019 and 2020 but differed $(P<0.05)$ between 2019 and 2020 in both sets of

593 cages (in 'with Ailanthus cages': $F_{1,29}=14.47 ; P=0.0001$; in 'without Ailanthus' cages:

$\left.594 \quad F_{1,29}=13.25 ; P=0.0001\right)$. Means within a column followed by asterisks are significantly different

595 (Bonferroni post hoc test: $P<0.05$ ). Black walnut trees were not included in the analysis because

596 most died during the 2019 studies and had to be replaced in spring of 2020. 


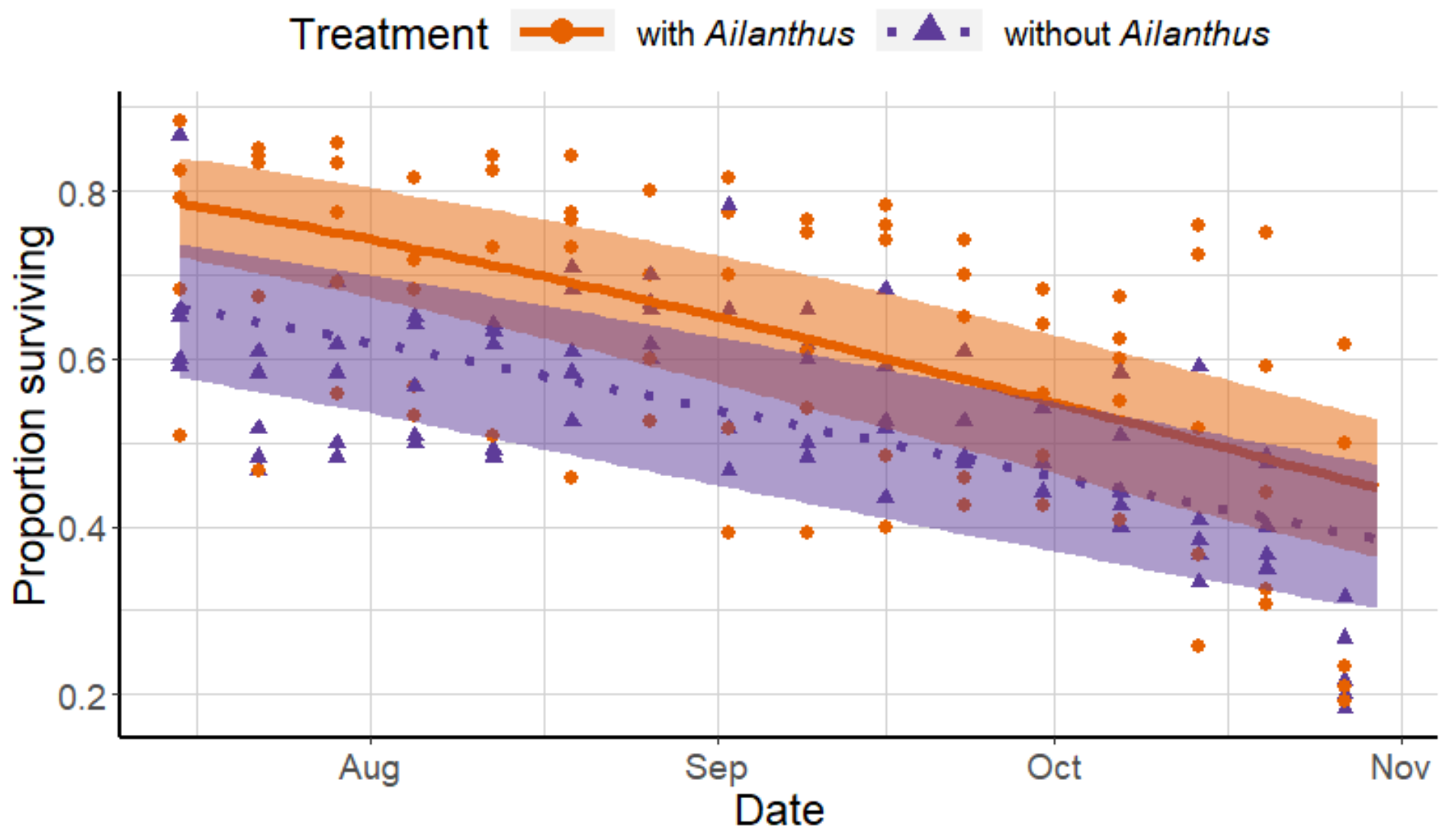

Figure 1

Proportion of Lycorma delicatula (nymphs and adults combined) that survived in enclosures with planted Ailanthus altissima, Acer saccharinum, Juglans nigra and Salix babylonica ('Ailanthus,' $\mathrm{n}=5$ enclosures) or enclosures with the same tree species except for the presence of Betula nigra in place of A. altissima ('without Ailanthus,' $n=5$ enclosures) from July 15 to November 4, 2020. Fitted binomial regression lines are shown, with shaded areas indicating $95 \%$ confidence intervals for predicted regression means. In total, 120 third-insta nymphs were released in each enclosure and their numbers and host tree associations were recorded weekly. 


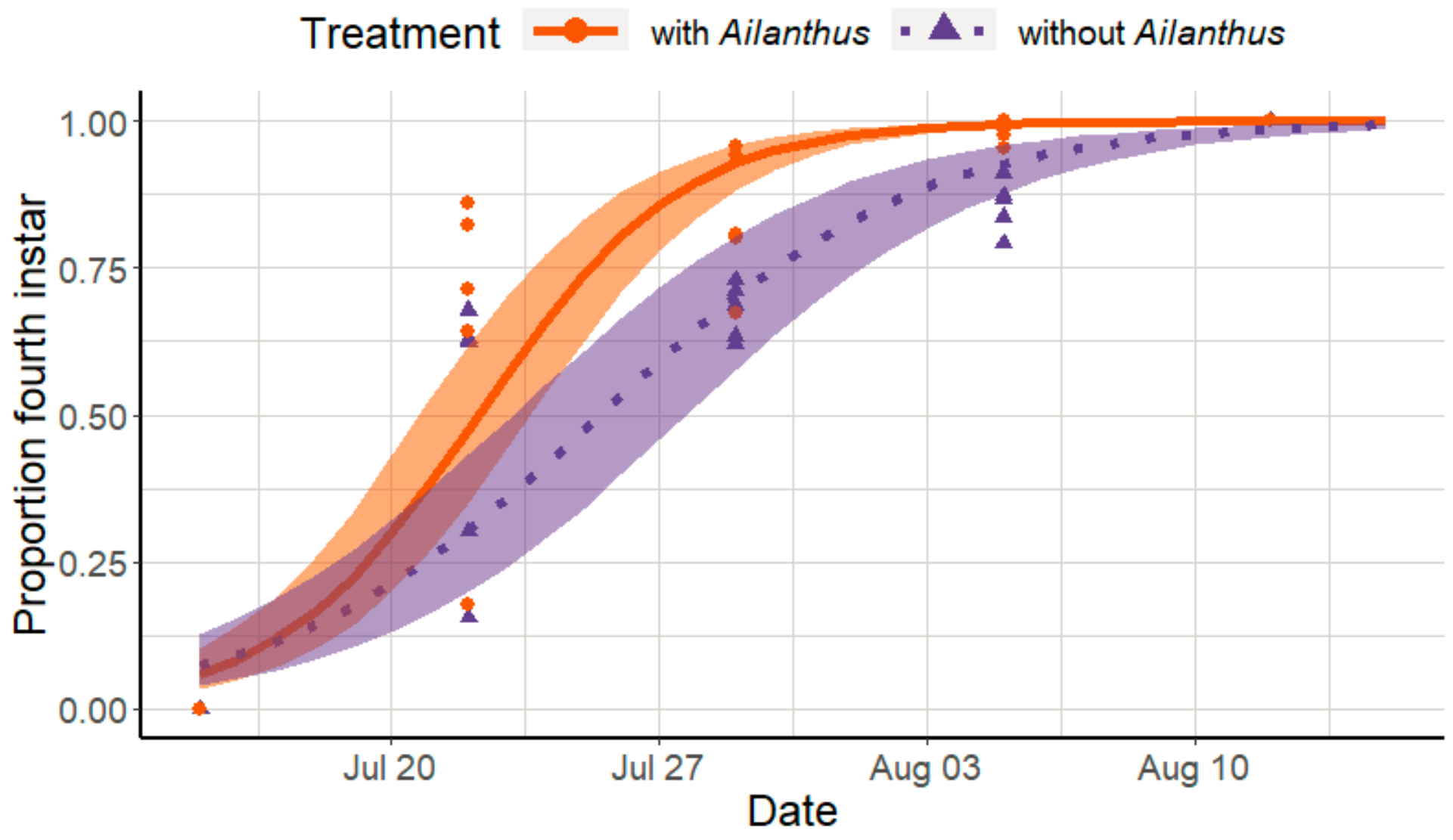

Figure 2

Proportion of L. delicatula that developed from the third to the fourth instar over time, with fitted logistic regression lines, in enclosures with and without Ailanthus altissima. 


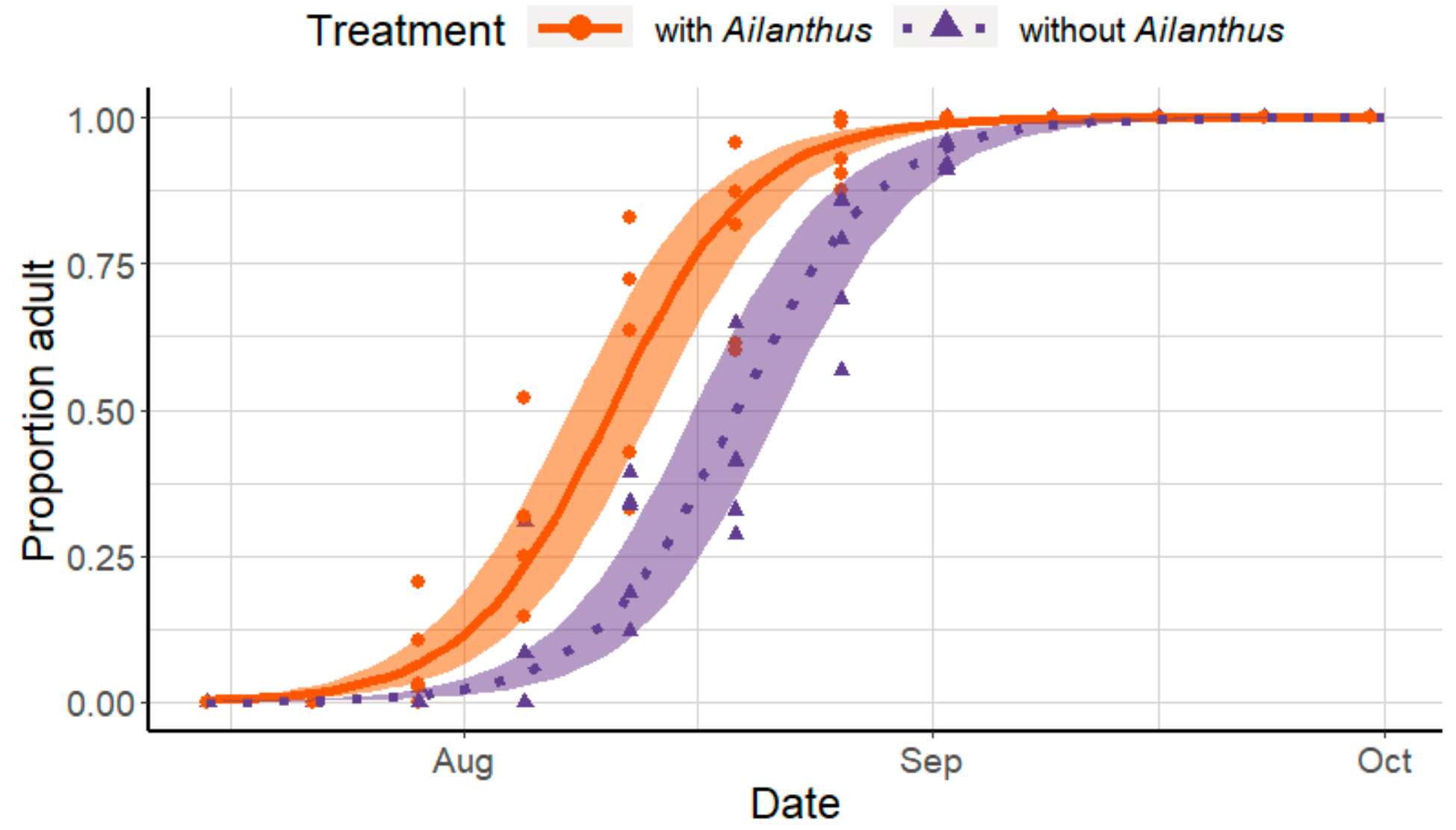

Figure 3

Proportion of L. delicatula that emerged as adults over time, with fitted logistic regression lines, for enclosures with and without Ailanthus altissima. 

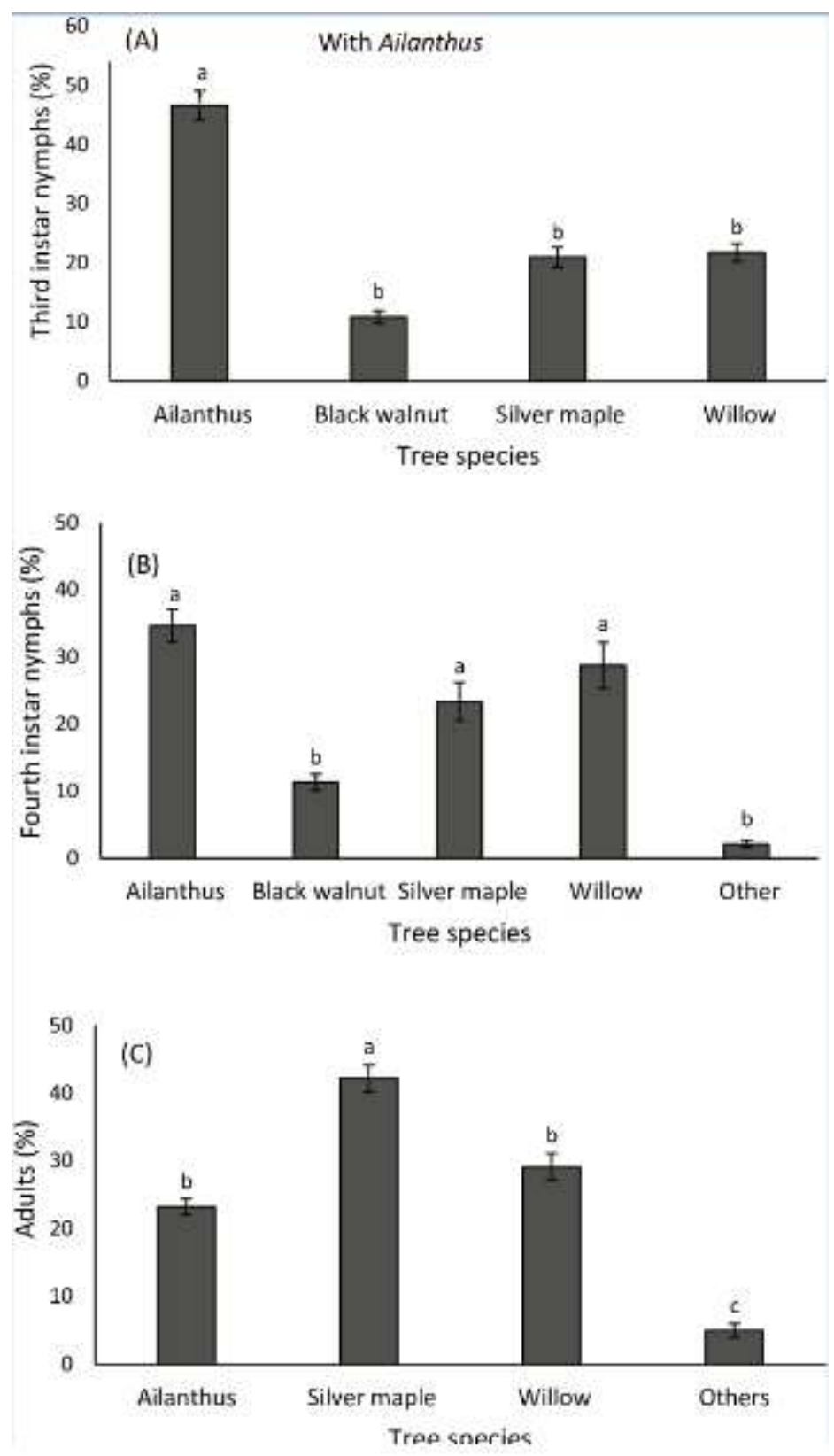

\section{Figure 4}

Mean ( \pm SE) proportion of Lycorma delicatula third instars (A) fourth instars (B) and adults (C) present on each tree species in enclosures with Ailanthus (Ailanthus altissima), silver maple (Acer saccharinum), black walnut (Juglans nigra) and willow (Salix babylonica) ( $n=5$ enclosures) from July 15 to November 4,2020 . Nymphs and adults found on annual plants $(2 \%)$ within the enclosure or on enclosure walls (98\%) are included as 'Others.' Means within a column followed by different letters are significantly different (Bonferroni post hoc test: $\mathrm{P}<0.05$ ). No adults were found on black walnut and no third instar nymphs were found on other surfaces. 

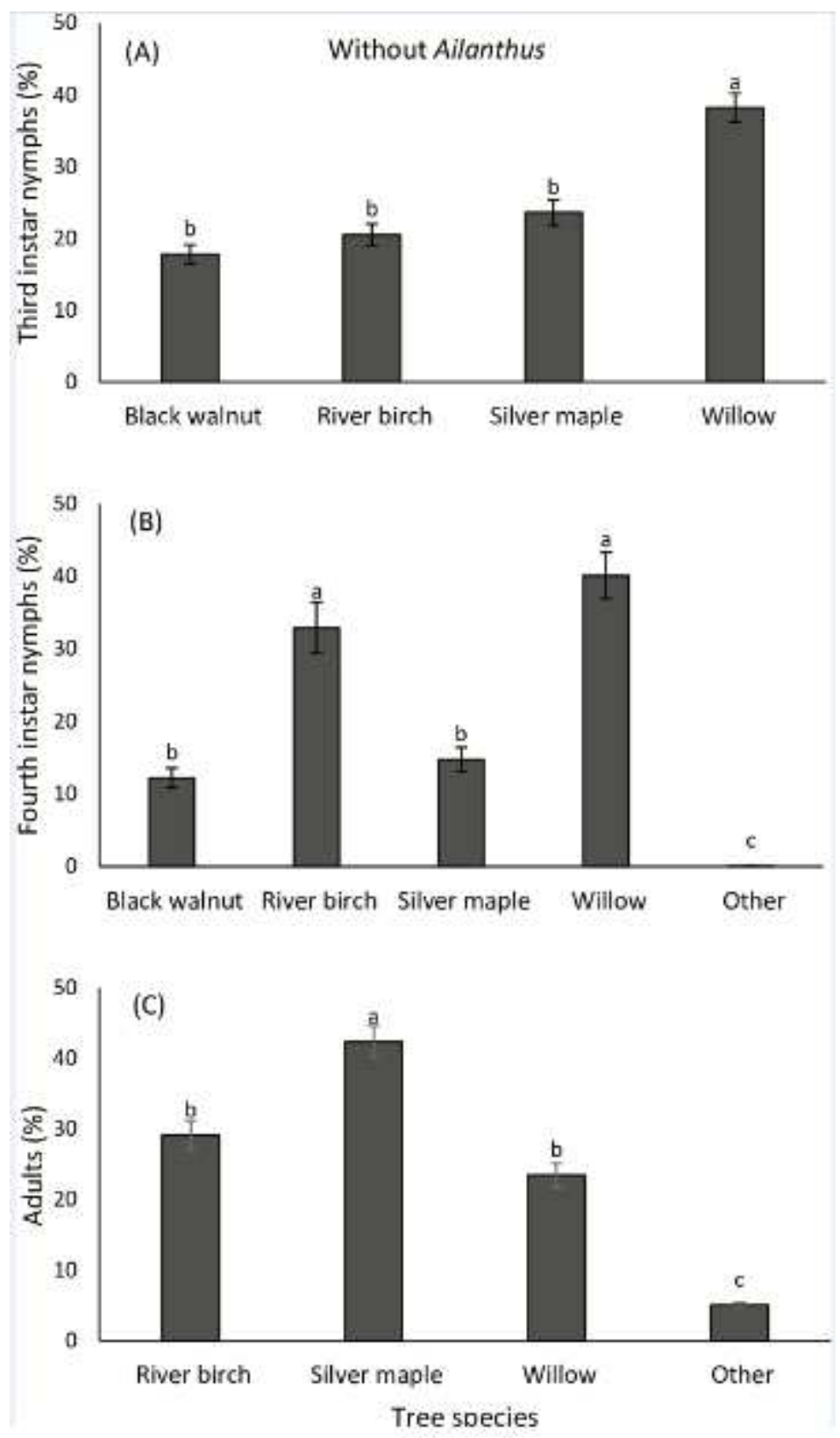

\section{Figure 5}

Mean $( \pm S E)$ proportion of Lycorma delicatula third instars (A), fourth instars (B) and adults (C) present on each tree species in enclosures with silver maple (Acer saccharinum), black walnut (Juglans nigra), willow (Salix babylonica) and river birch (Betula nigra) (without Ailanthus altissima, $n=5$ enclosures) from July 15 to November 4, 2020. Nymphs and adults found on other plants (2\%) within the enclosure or on enclosure walls (98\%) are included as 'Others.' Means within a column followed by different letters are significantly different (Bonferroni post hoc test: $\mathrm{P}<0.05$ ). No adults were found on black walnut and no third instar nymphs were found on other surfaces. 

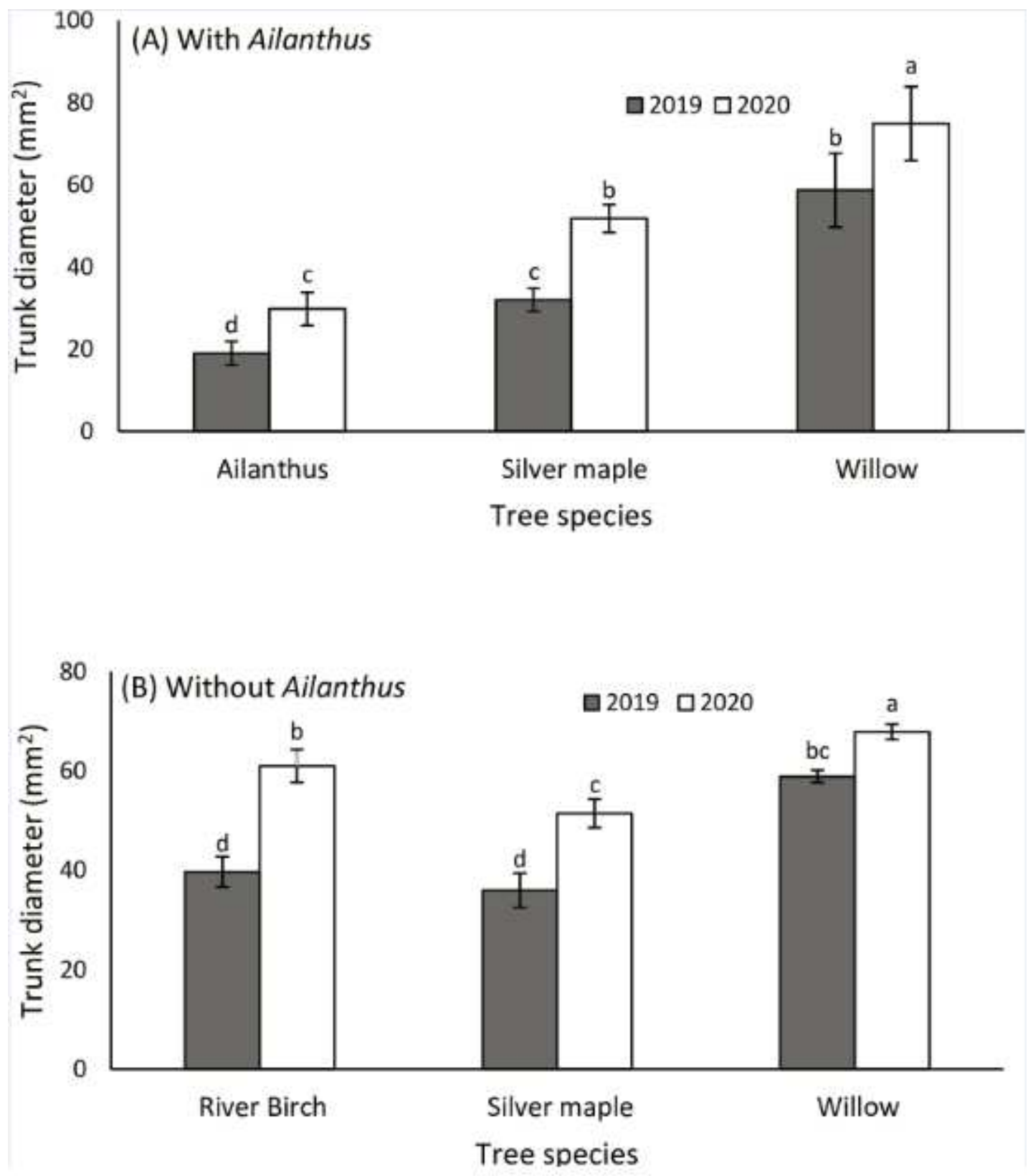

Figure 6

Mean $( \pm S E)$ trunk diameter $(\mathrm{mm})$ of tree species in enclosures with Ailanthus $(A)$ and without Ailanthus (B) ( $n=5$ enclosures) in 2019 and 2020. Measurements were made on October 31, 2019 and November 3 , 2020. Means within a column followed by different letters are significantly different (Bonferroni post hoc test: $P<0.05)$. Black walnut trees were not included in the analysis because most died during the 2019 studies and had to be replaced in spring of 2020 . 
(A) With Ailanthus
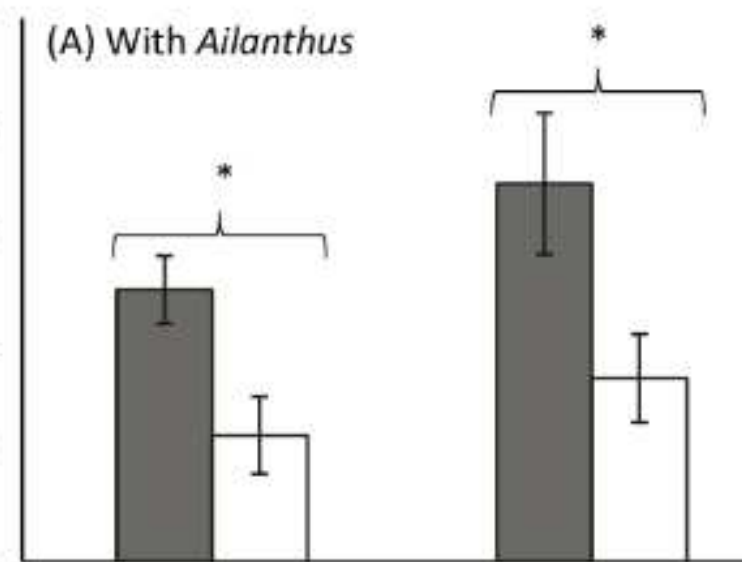

Ailanthus

Silver maple

Willow

Tree species

$\square 2019 \square 2020$

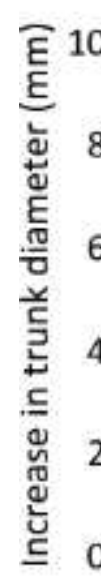

(B) Without Ailanthus

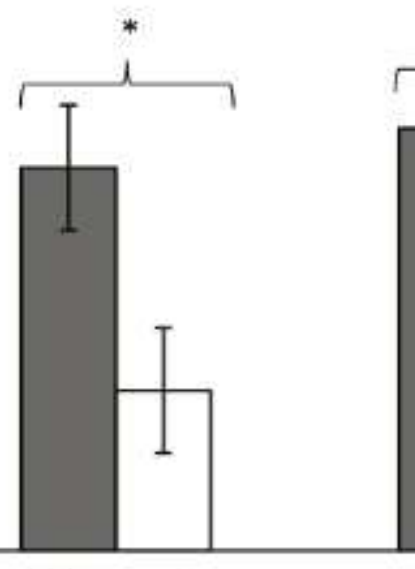

Silver maple

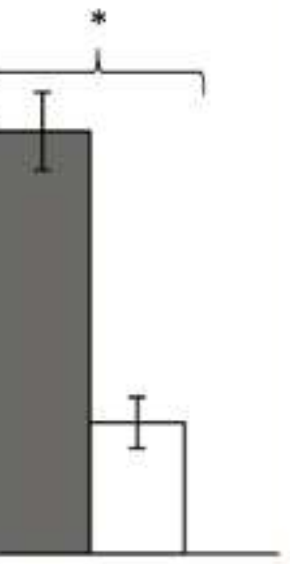

River Birch

Tree species

Willow

\section{Figure 7}

Mean $( \pm S E)$ increase in trunk diameter $(\mathrm{mm})$ of tree species in enclosures with Ailanthus $(A)$ and without Ailanthus (B) ( $n=5$ enclosures) in 2019 and 2020. Measurements were made on June 4 and October 31, 2019 , and July 8 and November 3, 2020. Increase in trunk diameter was obtained by subtracting trunk diameter data collected at the start of the experiment from those collected at the end of the experiment. Diameter increase did not differ $(P>0.05)$ between species in 2019 and 2020 but differed $(P<0.05)$ between 2019 and 2020 in both sets of cages (in 'with Ailanthus cages': F1,29=14.47; $P=0.0001$; in 'without Ailanthus' cages: $F 1,29=13.25 ; P=0.0001)$. Means within a column followed by asterisks are significantly different (Bonferroni post hoc test: $\mathrm{P}<0.05$ ). Black walnut trees were not included in the analysis because most died during the 2019 studies and had to be replaced in spring of 2020 . 